Check for updates

Cite this: Phys. Chem. Chem. Phys., 2019, 21, 718

Received 9th July 2018,

Accepted 3rd December 2018

DOI: $10.1039 / c 8 c p 04316 g$

rsc.li/pccp

\title{
A quasielastic and inelastic neutron scattering study of the alkaline and alkaline-earth borohydrides $\mathrm{LiBH}_{4}$ and $\mathrm{Mg}\left(\mathrm{BH}_{4}\right)_{2}$ and the mixture $\mathrm{LiBH}_{4}+\mathrm{Mg}\left(\mathrm{BH}_{4}\right)_{2} \dagger$
}

\author{
Luca Silvi, (D) $\ddagger^{* a}$ Zhirong Zhao-Karger, (D) bc Eva Röhm, ${ }^{\text {b }}$ Maximilian Fichtner, ${ }^{\text {bc }}$ \\ Winfried Petry and Wiebke Lohstroh ${ }^{a}$
}

\begin{abstract}
Quasielastic neutron scattering was used to investigate the low energy transfer dynamics of the complex borohydrides $\mathrm{Mg}\left(\mathrm{BH}_{4}\right)_{2}$ in the $\alpha$ - and $\beta$-modifications, $\mathrm{LiBH}_{4}$ in the low and high temperature crystal structure, and an 1:1 molar mixture of $\mathrm{LiBH}_{4}+\alpha-\mathrm{Mg}\left(\mathrm{BH}_{4}\right)_{2}$. All investigated compounds show a rich dynamic behaviour below an energy range of $\Delta E=10 \mathrm{meV}$ with the superposition of rotational dynamics of the constituent $\left[\mathrm{BH}_{4}\right]^{-}$anions and low lying lattice modes. For $\mathrm{Mg}\left(\mathrm{BH}_{4}\right)_{2}$, the rotational diffusion of the $\left[\mathrm{BH}_{4}\right]$ units was found to be much more activated in the metastable $\beta$-polymorph compared to the $\alpha$-phase, and the low lying lattice modes are even softer in the former crystal structure. In $\mathrm{Mg}\left(\mathrm{BH}_{4}\right)_{2}$, the structural phase transition is mainly governed by the lattice dynamics, while alkaline $\mathrm{LiBH}_{4}$ exhibits a transition of the $\left[\mathrm{BH}_{4}\right]$ rotations around the phase transition temperature. Ball milled $\mathrm{LiBH}_{4}+\alpha-\mathrm{Mg}\left(\mathrm{BH}_{4}\right)_{2}$ remains a physical mixture of the parent compounds and each component retains its characteristic dynamic signature up to the melting temperature.
\end{abstract}

\section{Introduction}

Complex tetraborohydrides are a class of materials that have been studied intensely for their high volumetric and gravimetric hydrogen content and their potential use in solid state hydrogen storage applications. However, high thermodynamic stability, sluggish kinetics, formation of by-products and poor reversibility make these materials still unsuitable for viable storage systems. Among the complex hydrides, the most investigated compounds are lithium-, magnesium-, and calcium borohydrides which exhibit high hydrogen contents of $18.4 \mathrm{wt} \%$ $\mathrm{H}_{2}\left(\mathrm{LiBH}_{4}\right), 14.9 \mathrm{wt} \% \mathrm{H}_{2}\left(\mathrm{Mg}\left(\mathrm{BH}_{4}\right)_{2}\right)$, and $11.6 \mathrm{wt} \% \mathrm{H}_{2}\left(\mathrm{Ca}\left(\mathrm{BH}_{4}\right)_{2}\right)$, respectively. ${ }^{1-5}$ In general, complex hydrides are salt like materials, composed of $\left[\mathrm{BH}_{4}\right]^{-}$anions where four hydrogen atoms are covalently bound around the central boron atom, and the positively charged alkaline or alkaline-earth cation.

\footnotetext{
${ }^{a}$ Heinz Maier-Leibnitz Zentrum (MLZ) und Physik Department E13, Technische Universität München, Lichtenbergstr. 1, Garching, Germany. E-mail: luca.silvi@helmholtz-berlin.de

${ }^{b}$ Karlsruher Institut für Technology, Institut für Nanotechnologie, P. O. Box 3640, D-76021 Karlsruhe, Germany

${ }^{c}$ Helmholtz-Institut Ulm (HIU), Helmholtzstr. 11, 89081 Ulm, Germany

$\dagger$ Electronic supplementary information (ESI) available. See DOI: 10.1039/c8cp04316g \$ Present address: Institut für Weiche Materie und funktionale Materialien (EMISFM), Helmholtz-Zentrum Berlin für Materialien und Energie, Hahn Meitner Platz 1, 14109 Berlin, Germany.
}

Their crystal structures and thermodynamic stability are governed by the structural arrangement of the $\left[\mathrm{BH}_{4}\right]$ units, yielding to rich phase diagrams especially for the alkaline-earth compounds. For instance in $\mathrm{Mg}\left(\mathrm{BH}_{4}\right)_{2}$, the observed polymorphs are almost degenerate in their ground state energy, yielding quite often to phase mixtures during preparation, or metastable states. ${ }^{6-8} \alpha-\mathrm{Mg}\left(\mathrm{BH}_{4}\right)_{2}$ is energetically most favourable at low temperatures and it can be obtained as a solvent free material from solution employing a specific drying procedure. ${ }^{4}$ Upon heating to $490 \mathrm{~K}$, the material undergoes a phase transition to the high temperature $\beta$-phase which then remains metastable during cooling down to, at least, $10 \mathrm{~K}^{4,9}$ Further polymorphs of $\mathrm{Mg}\left(\mathrm{BH}_{4}\right)_{2}$ include a porous $\gamma$-phase and a high pressure $\delta$-phase. ${ }^{9,10}$ Similarly, for $\mathrm{Ca}\left(\mathrm{BH}_{4}\right)_{2}$, there are four known crystal structures: $\alpha-, \alpha^{\prime}$ and $\gamma$-phase are considered low temperature phases, while $\beta$ is a high temperature phase. ${ }^{11-13}$ The hydrogen release properties differ slightly for the various polymorphs. ${ }^{14}$ The alkaline borohydrides, $\mathrm{LiBH}_{4}, \mathrm{NaBH}_{4}$ and $\mathrm{KBH}_{4}$ also show different crystal structures, but in contrast to their alkalineearth relatives, the observed structural phase transitions between low and high temperature crystal structures are fully reversible as the temperature is increased above or lowered below the respective transition temperatures. $\left(\mathrm{LiBH}_{4}: T=381 \mathrm{~K},{ }^{15}\right.$ $\mathrm{NaBH}_{4}: T=190 \mathrm{~K}^{16}$ and $\left.\mathrm{KBH}_{4}: T \approx 70 \mathrm{~K}^{17}\right)$.

The complexity and the number of different crystal modifications observed for $\mathrm{Mg}\left(\mathrm{BH}_{4}\right)_{2}$ is thought to be the result of the 
interplay between cation size and interaction between neighbouring $\left[\mathrm{BH}_{4}\right]^{-}$anions. ${ }^{18}$ In ionic crystals, the coordination number around the central cation is given by the ratio of the size of the metal cation in its appropriate oxidation state and the size of the anion. In the borohydrides, additionally, the orientation of the tetrahedral $\left[\mathrm{BH}_{4}\right]^{-}$anion, and the mutual repulsion of the hydrogen atoms (each carrying a negative partial charge) come into play. Energetically, a tridendentate orientation of the $\left[\mathrm{BH}_{4}\right]^{-}$towards the cation is most favourable, most unfavourable is the monodentate orientation which has not been found in any experimental crystal structure so far. ${ }^{18}$ For $\mathrm{Mg}^{2+}$, the ion radius yields a coordination number on the border between tetragonal and octagonal coordinations, and additionally, the tetrahedral $\left[\mathrm{BH}_{4}\right]$ can not be packed in a space filling manner. In combination with the various possibilities for the $\left[\mathrm{BH}_{4}\right]$ orientation, this yields to a variety of predicted and experimentally observed crystal phases which are almost degenerate in energy. ${ }^{6-8,18}$ This effect is supposed to be less pronounced in the alkaline borohydrides due to the lower cation charge.

From the above, it follows that the orientation of the $\left[\mathrm{BH}_{4}\right]$ units and their dynamics at non-zero temperatures have a significant impact on the stability of the compounds. In the alkaline borohydrides $\mathrm{LiBH}_{4}, \mathrm{NaBH}_{4}$ and $\mathrm{KBH}_{4}$, the crystal phase transition is accompanied by a change of the local rotational reorientation of the $\left[\mathrm{BH}_{4}\right]$ (order-disorder transition), moreover changes in the external $\left[\mathrm{BH}_{4}\right]$-vibrational modes have been measured using inelastic neutron spectroscopy (INS). ${ }^{19-22}$ INS has also been used to measure the low energy excitation spectra of $\alpha$ - and $\beta$-Ca $\left(\mathrm{BH}_{4}\right)_{2}$, showing that the two polymorphs differ in the vibrational frequency of the $\left[\mathrm{BH}_{4}\right]$ tetrahedra. $^{23}$ Measurements of the low energy transfer dynamics in these compounds are thus essential to understand the stability and binding in the borohydride compounds.

In the same context, multiple attempts to destabilize (or stabilize) borohydrides by the synthesis of dual cation compounds have been undertaken, i.e. stabilizing crystal structures that comprise two different cations balancing the negative $\left[\mathrm{BH}_{4}\right]^{-}$anions. Nakamori et $a .^{24}$ showed in first principles calculations that the thermodynamic stability of alkaline and alkaline-earth borohydrides correlates with the electronegativity of the cations. The use of dual cation compounds with an average intermediate electronegativity thus could offer a pathway to tune the hydrogen desorption properties to conditions more viable for applications. Dual cation compounds have been successfully synthesized and their structures were characterized for a series of $\mathrm{Li}-\mathrm{Zn}$ and $\mathrm{Na}-\mathrm{Zn}$ borohydrides ${ }^{25}$ or $\mathrm{M}-\mathrm{Sc}$ borohydrides (with $\mathrm{M}=\mathrm{Li}, \mathrm{Na}$, and $\mathrm{K}$ ), for an overview see ref. 26 . Moreover, mixed borohydride with $\mathrm{KBH}_{4}\left(\mathrm{Li}-\mathrm{K}-\right.$ borohydride, ${ }^{27}$ or $\left.\mathrm{Mg}-\mathrm{K}-\left(\mathrm{BH}_{4}\right)_{x}{ }^{28}\right)$ have been identified. However, for $\mathrm{LiBH}_{4}+\mathrm{Mg}\left(\mathrm{BH}_{4}\right)_{2}$ mixtures there are contradicting findings, and both, the physical mixture of powders has been reported ${ }^{29,30}$ as well as a dual cation compound. ${ }^{31,32}$

In this paper, we will report quasielastic (QENS) and inelastic neutron spectroscopy (INS) data to elucidate the low lying excitations and local reorientations in the alkali borohydride $\mathrm{LiBH}_{4}$, the alkaline-earth borohydrides $\alpha$ - and $\beta-\mathrm{Mg}\left(\mathrm{BH}_{4}\right)_{2}$, and an 1:1 molar mixture $\mathrm{LiBH}_{4}+\alpha-\mathrm{Mg}\left(\mathrm{BH}_{4}\right)_{2}$. All samples are investigated as a function of temperature and the dynamic properties for the various crystal modifications were thus explored. $\mathrm{LiBH}_{4}$ has already been intensely studied using QENS ${ }^{20,33-35}$ or INS $^{36}$ and we will briefly summarize our results as the baseline for discussion of the results for the 1:1 molar mixture $\mathrm{LiBH}_{4}+\alpha-\mathrm{Mg}\left(\mathrm{BH}_{4}\right)_{2}$ to further investigate the possibility of a dual cation borohydride.

At low temperature (LT-), the crystal structure of $\mathrm{LiBH}_{4}$ is orthorhombic (Pnma), and around $381 \mathrm{~K}$, a first order structural phase transition occurs to the hexagonal high temperature (HT-) phase $\left(\mathrm{P}_{3} \mathrm{mc}\right){ }^{37}$ After some controversy, it has been concluded that the hydrogen atoms are bonded to the central boron in an almost perfect tetrahedral shape in both crystal modifications. ${ }^{15}$ From synchrotron diffraction experiments, the distance between $\mathrm{B}$ and $\mathrm{H}\left(d_{\mathrm{B}-\mathrm{H}}\right)$ was estimated to be 1.16-1.26 in the HT-phase, ${ }^{15}$ whereas neutron diffraction experiments show $d_{\mathrm{B}-\mathrm{H}}=1.18-1.20 \AA$ at $302 \mathrm{~K}^{38}$ The cell parameters of the LT-crystal structure display a highly anisotropic temperature dependence and it was suggested that the structural phase transition is driven by anharmonic effects. ${ }^{15}$ The structural phase transition is accompanied by an order-disorder transition of the $\left[\mathrm{BH}_{4}\right]$ units. $^{19,20,38}$

The $\alpha$-modification of $\mathrm{Mg}\left(\mathrm{BH}_{4}\right)_{2}$ belongs to the $P 6_{1} 22$ symmetry space group with six non-equivalent positions of the $\mathrm{BH}_{4}$ tetrahedra. ${ }^{39}$ The $\beta$-phase has an orthorhombic Fddd structure in which five non-equivalent $\left[\mathrm{BH}_{4}\right]$ positions have been identified. The unit cell volume is almost the double of the $\alpha$-polymorph. Both $\alpha$ - and $\beta-\mathrm{Mg}\left(\mathrm{BH}_{4}\right)_{2}$ show anomalous thermal expansion, much more pronounced in the latter polymorph. ${ }^{39}$ In both crystal modifications, $\mathrm{Mg}$ atoms are surrounded by four $\left[\mathrm{BH}_{4}\right]$ tetrahedra leading to a strongly distorted tetrahedral environment. At a local level, each $\mathrm{Mg}$ atom is facing two hydrogens of the adjacent $\left[\mathrm{BH}_{4}\right]$ in a bidentate orientation, leading to an almost linear $\mathrm{Mg}-\mathrm{H}_{2}-\mathrm{B}-\mathrm{H}_{2}-\mathrm{Mg}$ chain, with two chains at $90^{\circ}$ at each $\mathrm{Mg}$-atom. The resulting $\mathrm{MgH}_{8}$ polygons form different membered rings in the respective crystal structures. The dynamics of the $\left[\mathrm{BH}_{4}\right]^{-}$anions has been studied by Nuclear Magnetic Resonance (NMR), Raman, infrared and inelastic neutron spectroscopy. NMR measurements on $\beta-\mathrm{Mg}\left(\mathrm{BH}_{4}\right)_{2}$ show that the rotational dynamics of the $\left[\mathrm{BH}_{4}\right]$ units is characterized by a broad distribution of activation energies, whereas, in $\alpha-\mathrm{Mg}\left(\mathrm{BH}_{4}\right)_{2}$, NMR measurements show three distinct jump processes, with significantly higher activation energies. ${ }^{40-42}$ The difference has been attributed to the different crystal structures and to the $\left[\mathrm{BH}_{4}\right]$ inequivalent crystallographic positions.

To our knowledge, so far there have been no measurements of the dynamic properties of an 1:1 molar mixture of $\mathrm{LiBH}_{4}+$ $\alpha-\mathrm{Mg}\left(\mathrm{BH}_{4}\right)_{2}$. The $1: 1$ ratio is close to the eutectic composition of the binary system with a melting point between 450 and $520 \mathrm{~K}^{30}$

\section{Experimental}

Neutron scattering measurements were performed at the cold direct geometry time-of-flight spectrometer TOFTOF operated by the Technische Universität München at the 
Heinz Maier-Leibnitz Zentrum (MLZ) in Garching, Germany. ${ }^{43,44}$ All measurements were performed in transmission mode, i.e. flat sample cells were oriented at $2 \theta=135^{\circ}$ with respect to the incoming beam. Data were corrected by subtracting the empty container contribution, accounting for the self-shielding factors, and normalization to a vanadium standard. For the analysis, the aluminium Bragg peaks arising from the sample environment and the sample cells were excluded. The obtained dynamic structure factor $S(Q, \omega)$ was binned into a regular grid in energy $(\hbar \omega)$ and momentum transfer $(Q)$. Due to the high incoherent scattering cross section of hydrogen, the signal registered at the detector is predominantly from hydrogen. Three different incident wavelengths were chosen to cover a large dynamic range. The settings were as follows (with $\delta E_{i}$ the FWHM of the resolution function at zero energy transfer):

(1) $\lambda_{1}=6 \AA$, with $\delta E_{1}=48 \mu \mathrm{eV}$ and $\Delta Q_{1}=0.2-1.8 \AA^{-1}$,

(2) $\lambda_{2}=3.5 \AA$, with $\delta E_{2}=200 \mu \mathrm{eV}$ and $\Delta Q_{2}=0.3-3 \AA^{-1}$.

(3) $\lambda_{3}=2.5 \AA$, with $\delta E_{3}=480 \mu \mathrm{eV}$ and $\Delta Q_{3}=0.5-4.2 \AA^{-1}$.

$\mathrm{LiBH}_{4}$ was purchased from Alpha Aesar, with $95 \%$ nominal purity. The material was used without further purification. Approximatively, $70 \mathrm{mg}$ of material was employed for the measurements, yielding to an estimated neutron transmission of $\sim 85 \%$. Measurements were performed with the incident neutron wavelength $\lambda_{3}$, and at 343,373 and $403 \mathrm{~K} \cdot \mathrm{Mg}\left(\mathrm{BH}_{4}\right)_{2}$ was prepared in the $\alpha$ - and $\beta$-crystal modifications as described in ref. 4 . In both polymorphs, the isotope ${ }^{11} \mathrm{~B}$ was used in order to minimize the neutron absorption. Approximatively, $200 \mathrm{mg}$ of $\mathrm{Mg}\left({ }^{11} \mathrm{BH}_{4}\right)_{2}$ were used, yielding to an estimated neutron transmission of $\sim 90 \%$. Measurements were performed at $\lambda_{1}$ and $\lambda_{3}$, in the temperature range between $11 \mathrm{~K}$ and $500 \mathrm{~K}$. Each temperature was measured for 3 hours, with additional 30 minutes of equilibration time. The data obtained for $\beta-\mathrm{Mg}\left(\mathrm{BH}_{4}\right)_{2}$ have been reported previously ${ }^{45}$ and the results will be discussed in conjunction with the data presented here.

A batch of 1:1 molar mixture of $\mathrm{LiBH}_{4}$ and $\alpha-\mathrm{Mg}\left(\mathrm{BH}_{4}\right)_{2}$ was prepared by high energy ball milling according to the procedure described ref. 30 . In the mixture, the isotope ${ }^{11} \mathrm{~B}$ was used in both lithium and magnesium borohydride. In total, approx. $160 \mathrm{mg}$ of material were used for the measurements. Measurements were performed at $\lambda_{2}$ and at 373,423 and $500 \mathrm{~K}$, i.e. below and above the crystal phase transitions of $\mathrm{LiBH}_{4}$ and $\mathrm{Mg}\left(\mathrm{BH}_{4}\right)_{2}$.

\section{Data analysis}

Generally, in the incoherent approximation, the scattering function $S(Q, \omega)$ for particles performing simultaneous but independent motions can be described as:

$$
S(Q, \omega)=S_{\text {trans }}(Q, \omega) \otimes S_{\text {rot }}(Q, \omega) \otimes S_{\text {vib }}(Q, \omega),
$$

i.e. it is given by the convolution of the scattering functions for translational diffusion, rotation and vibration, respectively. In borohydrides, in the temperature range studied here, relevant for the analysis are jump rotational diffusion and vibration processes. The scattering function of rotational motions is given by the sum of a $\delta$-function and a series of Lorentzian functions:

$$
S_{\text {rot }}(Q, \omega)=A_{0}(Q) \delta(\omega)+\sum_{i>0} A_{i}(Q) L_{i}(Q, \omega) .
$$

The Lorentzians $L_{i}(Q, \omega)$ are characterized by their half-width at half maximum (HWHM) $\Gamma_{i}$, which are independent of the momentum transfer $Q$ and related to the mean residence time between subsequent jumps, $\Gamma_{i} \sim \hbar \tau_{i}{ }^{-1}$. Because of the normalization condition of the scattering function, it is $\sum_{i>0} A_{i}(Q)=1-A_{0}(Q) \cdot A_{0}(Q)$ is the elastic incoherent structure factor of the rotation which depends on the spatial extension and its symmetry. For simple rotations, expressions for $A_{0}(Q)$ can be obtained analytically, see for example ref. 46 .

For the $\left[\mathrm{BH}_{4}\right]$ tetrahedra, the most likely rotational motions occur around a $C_{2}$ or $C_{3}$-symmetry axis of the tetrahedra (see Fig. 1), $A_{0}(Q)$ for both cases is given by

$$
A_{0, C_{2}}(Q)=A_{0, C_{3}}(Q)=\frac{1}{2}\left[1+j_{0}\left(\frac{2 \sqrt{2}}{\sqrt{3}} Q d_{\mathrm{B}-\mathrm{H}}\right)\right],
$$

$d_{\mathrm{B}-\mathrm{H}}$ is the boron-hydrogen distance and $j_{0}(x)$ is the zero order Bessel function, $j_{0}(x)=\sin x / x$. In the case there is no preferred $C_{2}$ or $C_{3}$-axis and all four hydrogen atoms exchange places with equal probability ( $C_{4}$ tumbling motion), $A_{0}(Q)$ reads: ${ }^{47}$

$$
A_{0, C_{4}}=\frac{1}{4}\left[1+3 j_{0}\left(\frac{2 \sqrt{2}}{\sqrt{3}} Q d_{\mathrm{B}-\mathrm{H}}\right)\right] .
$$

Vibrational motions are generally described by

$$
S_{\mathrm{vib}}(Q, \omega)=D(Q) \delta(\omega)+[1-D(Q)] S_{\mathrm{vib}}^{\mathrm{inel}}(Q, \omega),
$$

where $D(Q)$ denotes the Debye-Waller Factor (DWF). In the harmonic and isotropic approximation, it is given by $D(Q)=$ $\exp \left(-\left\langle u^{2}\right\rangle Q^{2} / 3\right)$, where $\left\langle u^{2}\right\rangle$ is the mean square displacement of the hydrogen atoms. In the one-phonon harmonic approximation, the inelastic scattering function $S_{\text {vib }}^{\text {inel }}(Q, \omega)$ can be described by a damped harmonic oscillator (DHO).

It has been shown previously ${ }^{45}$ that in $\beta-\mathrm{Mg}\left(\mathrm{BH}_{4}\right)_{2}$, low energy vibrational modes inhibit the separation of rotation and vibration parts of the QENS spectra. Therefore, for the

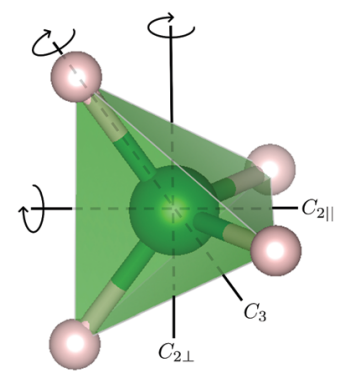

Fig. 1 Structure of the $\left[\mathrm{BH}_{4}\right]$ tetrahedra with three rotation axes: 3 -fold $120^{\circ}$ rotation axis $C_{3}$, and the 2 -fold $180^{\circ}$ rotation axes $\left(C_{2 \perp}\right.$ and $\left.C_{2 \|}\right)$. (green sphere) boron, and (small grey spheres) hydrogen. 
analysis, the convolution of $S_{\text {rot }}$ and $S_{\text {vib }}$ had to be considered in full. The measured $S(Q, \omega)$ was described using:

$$
\begin{gathered}
S(Q, \omega) \sim R_{\mathrm{res}}(\omega) \otimes\left[\mathrm{EISF} \cdot \delta(\omega)+\mathrm{QISF}_{L_{1}} \cdot L_{1}(\Gamma, Q)\right. \\
\left.+\mathrm{QISF}_{\mathrm{vib}} \cdot \operatorname{DHO}\left(Q, \omega_{q}, \Gamma_{\mathrm{DHO}}\right)\right]+\operatorname{bg}(Q),
\end{gathered}
$$

where the prefactors EISF, QISF $_{L_{1}}$ and QISF $_{\text {vib }}$ give the partial contribution of the elastic, quasielastic and inelastic components of the scattered intensity. $R_{\text {res }}(\omega)$ is the (measured) resolution function of the instrument and the linear background $\operatorname{bg}(Q)$ takes motions into account that are outside the observation time window of the experiment. Details on the derivation of the fit function can be found in the ESI. $\dagger$ As a result of the fit, the structure factors EISF, QISF $_{L_{1}}$ and QISF $_{\text {vib }}$ are obtained, as well as the HWHM $\Gamma_{1}$ proportional to the time scale of the jump rotation. The factors EISF, QISF $_{L_{1}}$ and QISF $_{\text {vib }}$ depend on the rotational elastic incoherent structure factor, $A_{0}(Q)$, the fraction of activated rotations, $1-p$ and the DebyeWaller Factor, $D(Q)$ as follows:

$$
\begin{gathered}
\operatorname{EISF}=D(Q)\left[p+(1-p) A_{0}(Q)\right] \\
\operatorname{QISF}_{L_{1}}=D(Q)(1-p)\left[1-A_{0}(Q)\right] \\
\operatorname{QISF}_{\mathrm{vib}}=1-D(Q) .
\end{gathered}
$$

$A_{0}(Q), p$ and $D(Q)$ are thus obtained from a simultaneous fit of the prefactors to eqn (7)-(9). The equations above are valid assuming only a single rotation with characteristic jump frequency $\tau^{-1} \sim \Gamma / \hbar$. The extension for two characteristic rotation modes having distinct time scales is given in the ESI. $\dagger$

\section{Results and discussion}

\section{$4.1 \alpha-\mathrm{Mg}\left(\mathrm{BH}_{4}\right)_{2}$}

Measurements of $\alpha-\mathrm{Mg}\left(\mathrm{BH}_{4}\right)_{2}$ were performed at $\lambda_{1}=6 \AA$ and $\lambda_{3}$ $=2.5 \AA$ and the obtained $S(Q, \omega)$ are shown in Fig. 2 and 3, respectively. Measurements were taken at temperatures from 11 to $500 \mathrm{~K}$. Above $490 \mathrm{~K}, \alpha-\mathrm{Mg}\left(\mathrm{BH}_{4}\right)_{2}$ transforms into the $\beta$-phase. The measurements at $6 \AA$ (probing timescales up to $\sim 16 \mathrm{ps}$ )

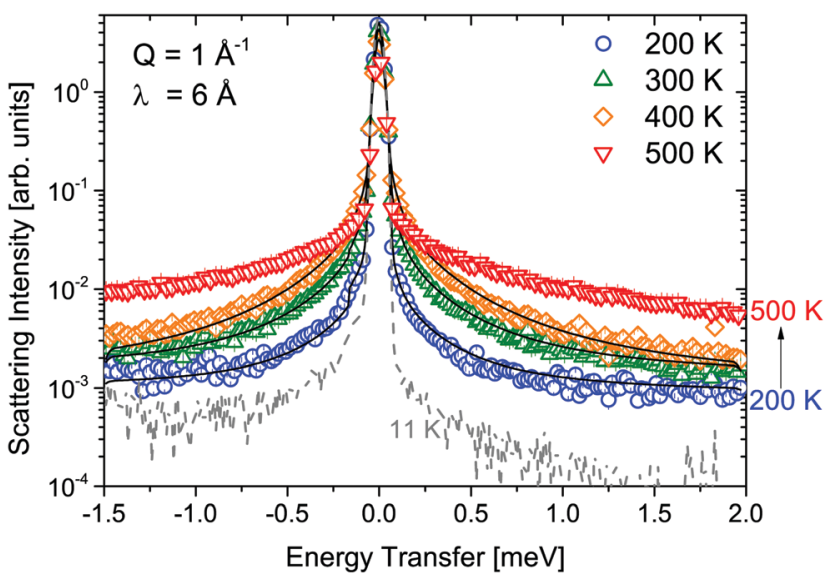

Fig. $2 \alpha-\mathrm{Mg}\left(\mathrm{BH}_{4}\right)_{2}: S(Q, \omega)$ measured at $\lambda_{1}=6 \AA$ and at $11,200,300,400$ and $500 \mathrm{~K}$. The solid black lines represent the fit to the data. The vertical error bars denote $\pm 1 \sigma$.

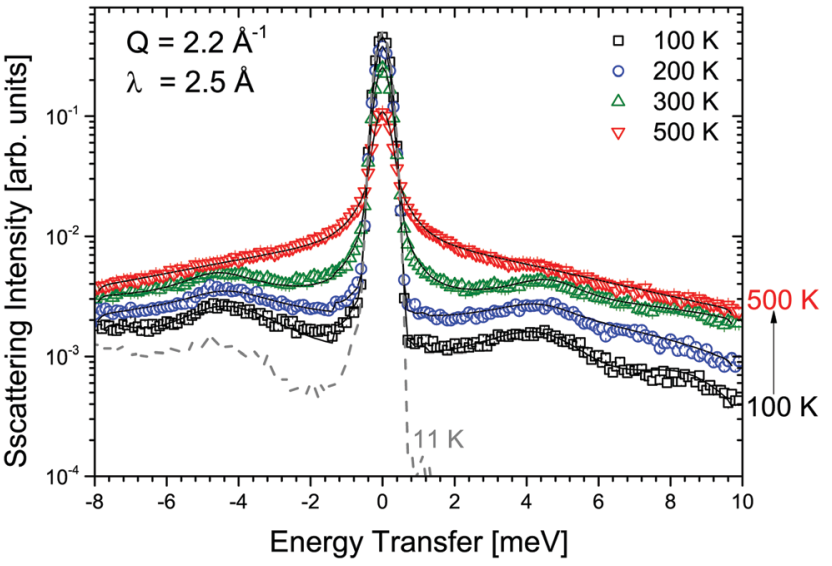

Fig. $3 \alpha-\mathrm{Mg}\left(\mathrm{BH}_{4}\right)_{2}: S(Q, \omega)$ measured at $\lambda_{3}=2.5 \AA$ and at $11,100,200,300$ and $500 \mathrm{~K}$. The solid black lines represent the fit to the data. Gray dashed line: $11 \mathrm{~K}$ (resolution), black squares: $100 \mathrm{~K}$, blue circle: $200 \mathrm{~K}$, green up triangles: $300 \mathrm{~K}$, and red down triangles: $500 \mathrm{~K}$. Data measured at $400 \mathrm{~K}$ have been omitted for clarity. The vertical error bars denote $\pm 1 \sigma$.

show a quasielastic broadening already at $200 \mathrm{~K}$, and its contribution increases with increasing temperature. When shorter time scales are probed (2.5 A-data, timescales up to $\sim 1.6 \mathrm{ps}$ ), the spectra are dominated by inelastic excitations that are observed in addition to the weak quasielastic signal around the elastic line. With the phase transition to the $\beta$-phase, both the quasielastic and inelastic signals undergo a distinct transformation and the data measured at $500 \mathrm{~K}$ were consistent with the findings published for $\beta-\mathrm{Mg}\left(\mathrm{BH}_{4}\right)_{2} \cdot{ }^{45}$ The low lying excitations in $\alpha-\mathrm{Mg}\left(\mathrm{BH}_{4}\right)_{2}$ have not been reported in previous studies of hydrogen dynamics in the $\alpha$-phase. ${ }^{48,49}$ The data analysis was conducted as described in the previous section. Both data sets could be fitted using a combination of quasielastic and inelastic components. The results of the fits are included in Fig. 2 and 3 (solid lines). The measurements at longer time scales ( $6 \AA$ data) indicate that there are two quasielastic processes, with distinct $\Gamma_{1, \alpha}$ and $\Gamma_{2, \alpha}$ (both independent of $Q$ ) in addition to the vibrational part (modeled as a flat background). The values of $\Gamma_{1, \alpha}$ and $\Gamma_{2, \alpha}$ obtained for the quasielastic components are given in Table 1.

Surprisingly, $\Gamma_{1, \alpha}$ and $\Gamma_{2, \alpha}$ were, within the experimental uncertainty, independent of temperature. At $500 \mathrm{~K}$, the $\beta$-modification is reached and both widths showed a steep increase, indicative for the quickening of the motions.

Table 1 Widths $\Gamma_{1, \alpha}$ and $\Gamma_{2, \alpha}$ obtained from the fits of the measurements of $\alpha-\mathrm{Mg}\left(\mathrm{BH}_{4}\right)_{2}$ at $6 \AA$. No quasielastic signal was observed at $100 \mathrm{~K}$. On the right side of the table the corresponding values $\Gamma_{i, \beta}$ for $\beta-\mathrm{Mg}\left(\mathrm{BH}_{4}\right)_{2}$ are listed, data taken from ref. 45

\begin{tabular}{lllll}
\hline$T[\mathrm{~K}]$ & $\Gamma_{1, \alpha}[\mu \mathrm{eV}]$ & $\Gamma_{2, \alpha}[\mu \mathrm{eV}]$ & $\Gamma_{1, \beta}[\mu \mathrm{eV}]$ & $\Gamma_{2, \beta}[\mu \mathrm{eV}]$ \\
\hline 100 & - & - & - & - \\
200 & $30 \pm 60$ & $280 \pm 150$ & $33 \pm 2$ & $330 \pm 50$ \\
300 & $26 \pm 30$ & $300 \pm 60$ & $73 \pm 11$ & $350 \pm 40$ \\
400 & $39 \pm 3$ & $300 \pm 50$ & $80 \pm 8$ & $500 \pm 60$ \\
500 & $100 \pm 20^{a}$ & $670 \pm 99^{a}$ & $110 \pm 20$ & $550 \pm 80$
\end{tabular}

${ }^{a}$ At $500 \mathrm{~K}$, both samples are in the $\beta$-modification. 
Table 2 Mean resident times $\tau_{i, \alpha \mid \beta}$ of $\mathrm{H}$ atoms between rotational jumps. $\tau_{i, \alpha \mid \beta}=2 \hbar / \Gamma_{i, \alpha \mid \beta}$ for a $C_{2}$ rotational model. In the case of $C_{3}$ jump rotations $\tau_{i, \alpha \mid \beta}=3 \hbar / 2 \Gamma_{i, \alpha \mid \beta}$. On the right side of the table, the corresponding values for $\beta-\mathrm{Mg}\left(\mathrm{BH}_{4}\right)_{2}$ are listed, data taken from ref. 45

\begin{tabular}{lccll}
\hline$T[\mathrm{~K}]$ & $\tau_{1, \alpha}[\mathrm{ps}]$ & $\tau_{2, \alpha}[\mathrm{ps}]$ & $\tau_{1, \beta}[\mathrm{ps}]$ & $\tau_{2, \beta}[\mathrm{ps}]$ \\
\hline 100 & - & - & - & - \\
200 & $43 \pm 90$ & $5 \pm 3$ & $40 \pm 2$ & $4.0 \pm 0.6$ \\
300 & $51 \pm 58$ & $4.3 \pm 0.8$ & $18 \pm 3$ & $3.7 \pm 0.4$ \\
400 & $33 \pm 2$ & $4.4 \pm 0.7$ & $16 \pm 2$ & $2.6 \pm 0.3$ \\
500 & $13.2 \pm 3.0^{a}$ & $1.9 \pm 0.3^{a}$ & $12 \pm 2$ & $2.4 \pm 0.3$
\end{tabular}

${ }^{a}$ At $500 \mathrm{~K}$, both samples are in the $\beta$-modification.

In comparison, the metastable $\beta$-phase exhibited slightly faster motions and a larger temperature dependence at temperatures below $500 \mathrm{~K}$. Similarly to the $\alpha$-phase, two rotational motions were identified and the values $\Gamma_{i, \beta}$ are included in Table 1 (values taken from ref. 45). Table 2 shows the mean resident times of $\mathrm{H}$ atoms between two successive jumps around the $C_{2}$ rotation axis, together with the $\beta-\mathrm{Mg}\left(\mathrm{BH}_{4}\right)_{2}$ data in the same temperature range.

The prefactors EISF, QISF $L_{L_{1}, \alpha}$ and QISF $_{L_{2}, \alpha}$ obtained from the fits to $S(Q, \omega)$ are shown in Fig. 4 together with a simultaneous fit to eqn (S14)-(S16), in the ESI. $\dagger$ The result indicated that both rotational motions are hindered at low temperatures, and the

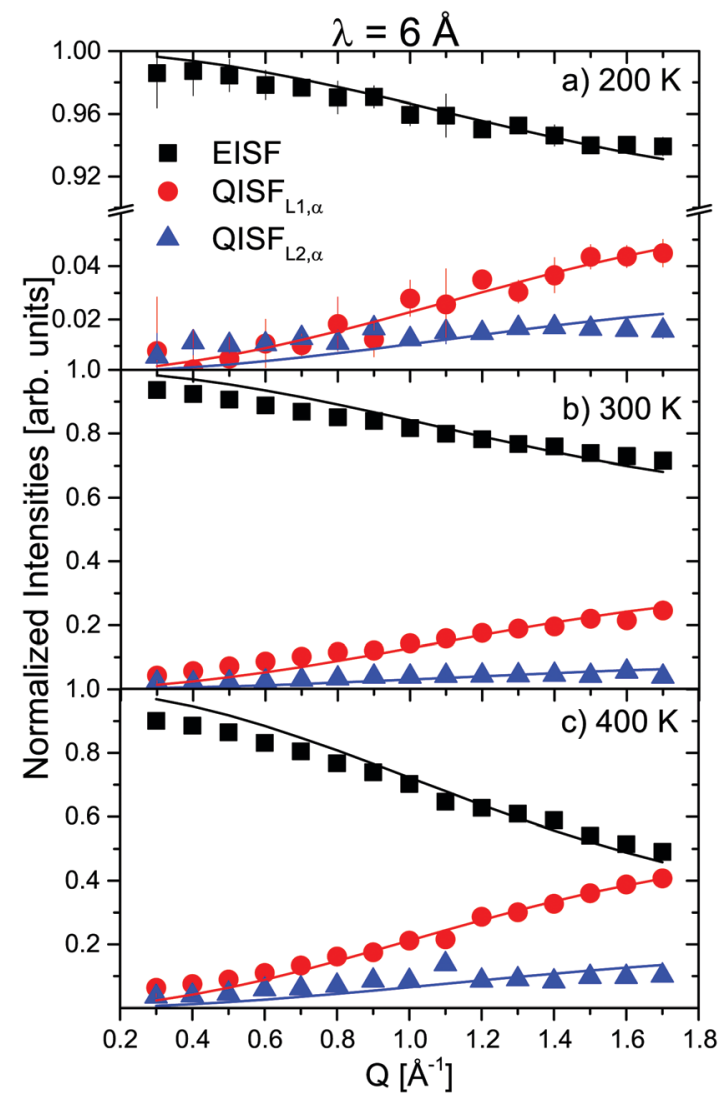

Fig. $4 \alpha-M g\left(B_{4}\right)_{2}$ : EISF (black squares), QISF $_{L_{1}, \alpha}$ (red circles) and $\operatorname{QISF}_{L_{2}, \alpha}$ (blue triangles) at different temperatures ( 6 data). Solid lines represent fit to the data according to eqn (S14)-(S16), in the ESI. $\dagger$ The vertical error bars denote $\pm 1 \sigma$. data were consistent with rotations around either the $C_{2}$ or $C_{3}$ symmetry axes of the tetrahedra. The data measured at $2.5 \AA$ were mainly characterized by the presence of inelastic excitations at energy transfers $\Delta E_{1} \sim \pm 4.2 \mathrm{meV}$ and $\Delta E_{2} \sim 8 \mathrm{meV}$. The excitations did not show any dispersion, and their position did not change with increasing temperature. A quasielastic signal could be distinguished at $300 \mathrm{~K}$ and above, however only at $500 \mathrm{~K}$, it became considerably larger compared to the inelastic parts, i.e. only after the sample has transformed to the $\beta$-phase. From the 6 A measurements, it was clear that the onset of the rotational motions is around $200 \mathrm{~K}$, however, the expected width was too close to the energy resolution and the signal was too weak to discern at low temperatures in the $2.5 \AA$ measurements. The narrower of the two Lorentzians was hidden in the experimental resolution at all measured temperatures. Therefore, the analysis of the $2.5 \AA$ data below $500 \mathrm{~K}$ shows two DHOs and one quasielastic component in addition to the elastic line. The results of the fits are plotted in Fig. 3 (solid lines), and the structure factors EISF and QISF and QISF $_{\text {vib }}$ are shown in Fig. 5.

The EISF and QISFs factors were evaluated using eqn (7)-(9). In agreement with the $6 \AA$ results, hindered rotations around the $C_{2}$ or $C_{3}$ axis were observed at $300 \mathrm{~K}$ and above, with only a limited fraction of the $\left[\mathrm{BH}_{4}\right]$ tetrahedra taking part in the

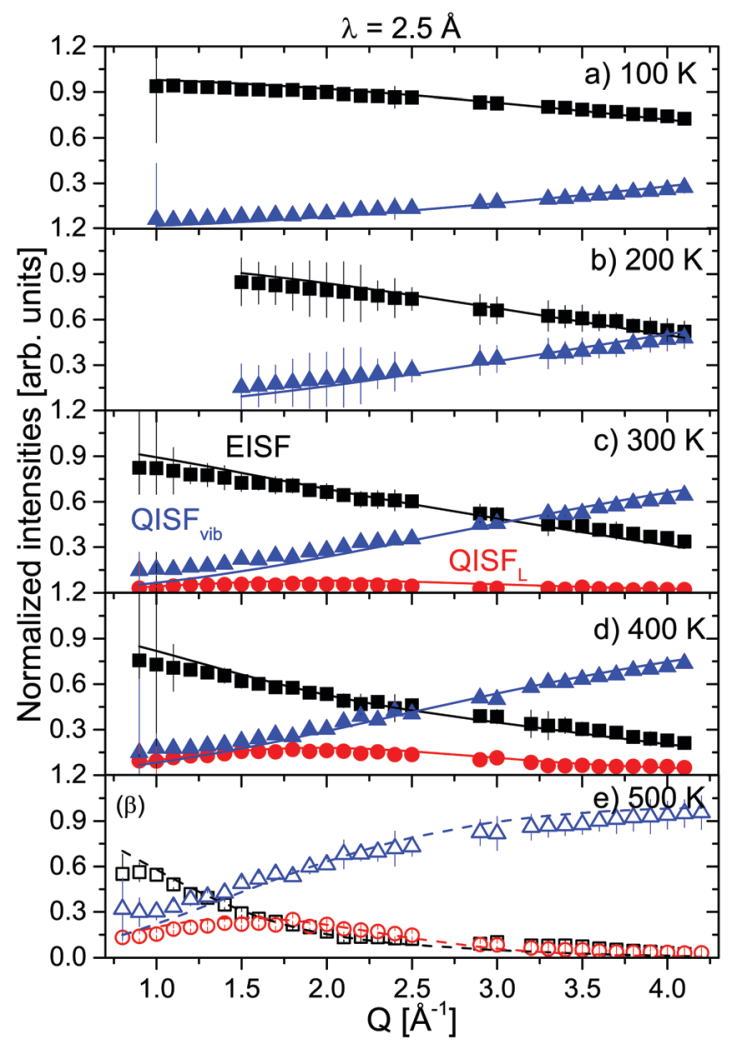

Fig. $5 \alpha-M g\left(\mathrm{BH}_{4}\right)_{2}$ : EISF (black squares), $\mathrm{QISF}_{L}$ (red circles) and $\mathrm{QISF}_{\text {vib }}$ (blue triangles) measured at $2.5 \AA$ and at 100, 200, 300, 400 and $500 \mathrm{~K}$. Solid lines represent the fit to data according to eqn (7)-(9). Panel (e) $500 \mathrm{~K}$ shows open symbols to distinguish between $\alpha$ - and $\beta$-phases. The vertical error bars denote $\pm 1 \sigma$. 


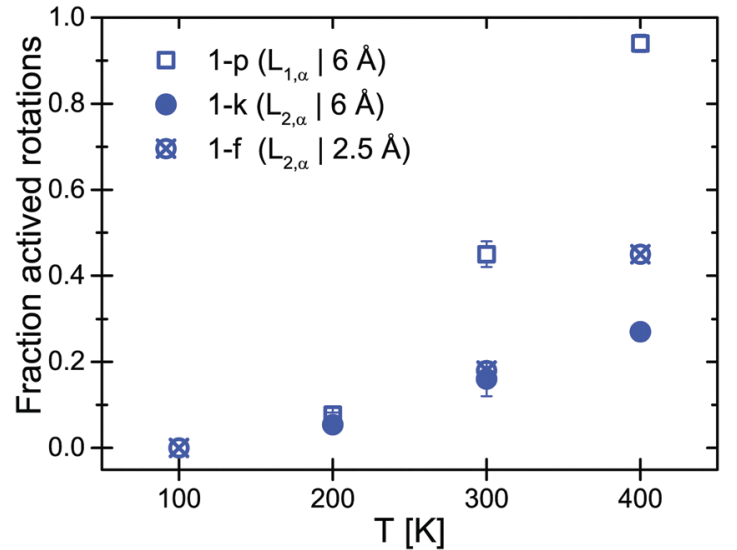

Fig. $6 \alpha-M g\left(B H_{4}\right)_{2}$ : fraction of the activated rotation processes $(1-p)$ and $(1-k)$ derived from EISF and QISF at $6 \AA$ (blue open squares and solid circles) and $(1-f)$ obtained from the $2.5 \AA$ measurement (crossed circles). The vertical error bars denote $\pm 1 \sigma$.

rotations ( $\sim 20 \%$ at $300 \mathrm{~K}$ and $\sim 40 \%$ at $400 \mathrm{~K}$ ) (see Fig. 6). Apparently, the inequivalent $\left[\mathrm{BH}_{4}\right]$ sites in $\alpha-\mathrm{Mg}\left(\mathrm{BH}_{4}\right)_{2}$ have different activation energies and only in the $\beta$-modification, all rotations are activated in the observation time window.

Fig. 7 shows the mean square displacement $\left\langle u^{2}\right\rangle$ obtained from the Debye-Waller-Factor $D(Q) .\left\langle u^{2}\right\rangle$ increases linearly in the $100-400 \mathrm{~K}$ temperature range with $\left\langle u^{2}\right\rangle=(6.7 \pm 0.2) \times$ $10^{-4} \times T[\mathrm{~K}] \AA^{2}$. The transition to the $\beta$-phase is marked by a jump-like increase of $\left\langle u^{2}\right\rangle$.

The two investigated polymorphs of $\mathrm{Mg}\left(\mathrm{BH}_{4}\right)_{2}, \alpha$ and $\beta$, exhibit quite different low energy dynamics, as shown above. Therefore, the analysis was mainly focused on the quasielastic scattering contribution and the local reorientation. To focus on the low energy excitation spectrum, a plot of the imaginary part of the dynamic susceptibility, $\chi^{\prime \prime}$ is shown in Fig. 8 . The latter was calculated from $\frac{1}{\pi} \chi^{\prime \prime}=S(Q, \omega)\left(1-\exp \left(-\frac{\hbar \omega}{k_{\mathrm{B}} T}\right)\right)$, with $k_{\mathrm{B}}$

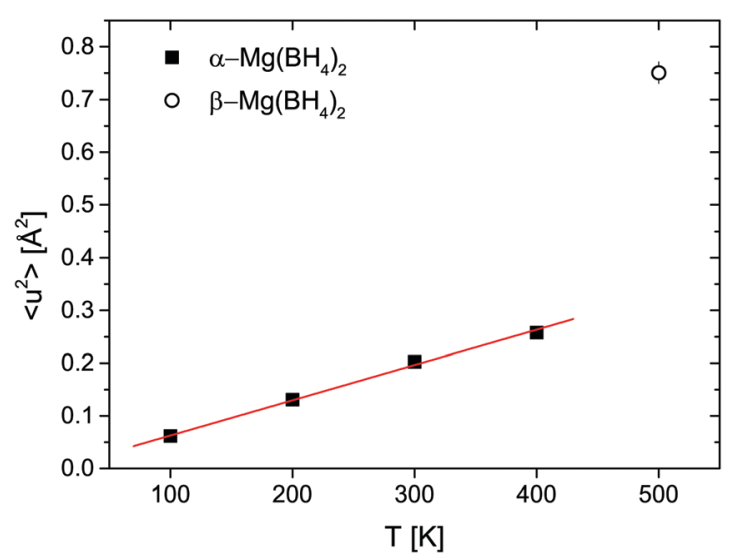

Fig. $7 \alpha-\mathrm{Mg}\left(\mathrm{BH}_{4}\right)_{2}$ : mean square displacement $\left\langle u^{2}\right\rangle$ as a function of temperature $T$. The red line is a linear fit to the data, in order to extract the temperature dependence: $\left\langle u^{2}\right\rangle=(6.7 \pm 0.2) \times 10^{-4} \times T[K] \AA^{2}$. Open symbols show data at $500 \mathrm{~K}$, where the system is already in the $\beta$ polymorph. The vertical error bars denote $\pm 1 \sigma$.

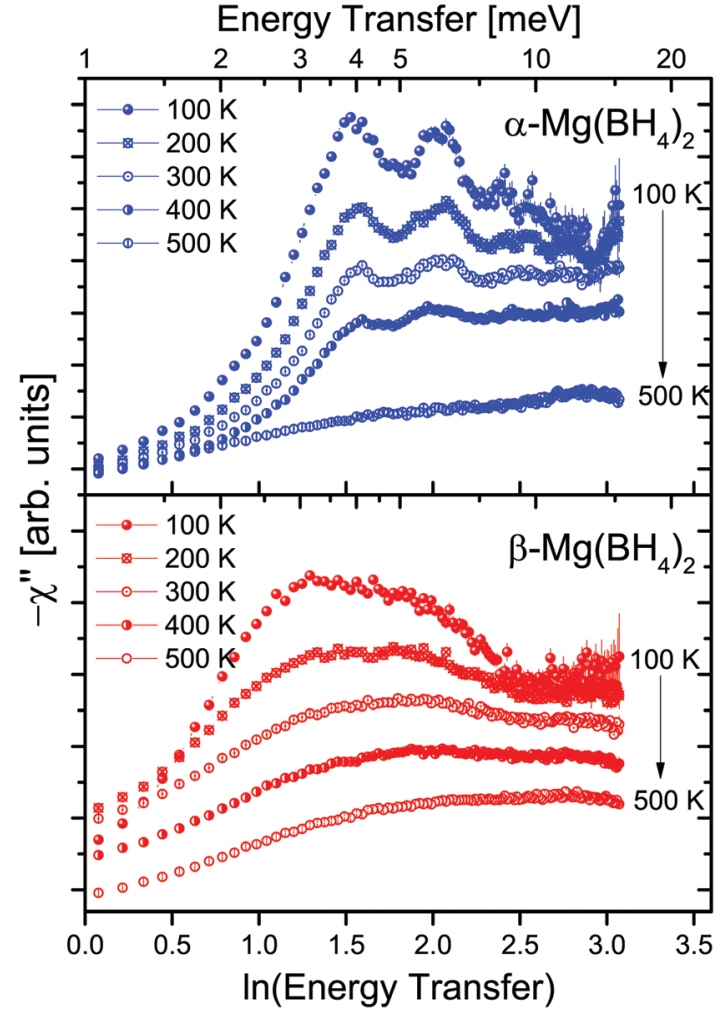

Fig. $8-\chi^{\prime \prime}$ as a function of In (energy transfer) and at different tempera-

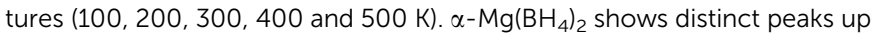
to high temperatures while $\beta-\mathrm{Mg}\left(\mathrm{BH}_{4}\right)_{2}$ has a much broader and slightly softer low energy spectrum. Data are summed for $Q=1.5-4.25 \AA^{-1}$. The increase towards low energy transfers is due to the quasielastic contributions. The vertical error bars denote $\pm 1 \sigma$.

the Boltzmann constant. Data were summed over $Q$ in the $1.5 \leq Q \leq 4.25 \AA^{-1}$ range. For $\alpha-\mathrm{Mg}\left(\mathrm{BH}_{4}\right)_{2}$, distinct peaks at around 4.2 and $8 \mathrm{meV}$ are visible which hardly change with temperature. In contrast, the $\beta$-polymorph has slightly softer low energy excitations and the features are much broader and less defined. The plot underlines that $\beta-\mathrm{Mg}\left(\mathrm{BH}_{4}\right)_{2}$ shows more dynamical disorder compared to the $\alpha$-phase, starting already at temperatures as low as $200 \mathrm{~K}$. This is also reflected in the mean square displacement $\left\langle u^{2}\right\rangle$, as illustrated in Fig. 9. The mean square displacement of $\alpha-\mathrm{Mg}\left(\mathrm{BH}_{4}\right)_{2}$ follows a linear relationship with increasing temperature. In the $\beta$-modification, $\left\langle u^{2}\right\rangle$ follows approximately the same relationship below $200 \mathrm{~K}$, but between 200 and $300 \mathrm{~K}$, a jump like increase is observed. In the same temperature region, the jump rotation processes in $\beta-\mathrm{Mg}\left(\mathrm{BH}_{4}\right)_{2}$ become fully activated ${ }^{45}$ whereas the rotation modes in $\alpha-\mathrm{Mg}\left(\mathrm{BH}_{4}\right)_{2}$ are still significantly hindered even at $400 \mathrm{~K}$. Incidentally, the anomalous lattice expansion observed in $\beta-\mathrm{Mg}\left(\mathrm{BH}_{4}\right)_{2}$ shows a change from contraction to the expansion of the $a$-lattice parameter around $200 \mathrm{~K}$ and the opposite for the $b$-axis lattice parameter, indicating a link between the local rotational dynamics, lattice dynamics and structure. In $\alpha-\mathrm{Mg}\left(\mathrm{BH}_{4}\right)_{2}$, anomalous expansion is much smaller and it is restricted to temperatures below $200 \mathrm{~K}^{39}$

The jump frequencies of the rotations in $\alpha-\mathrm{Mg}\left(\mathrm{BH}_{4}\right)_{2}$ appeared to be almost independent of temperature (see Table 1), however, 


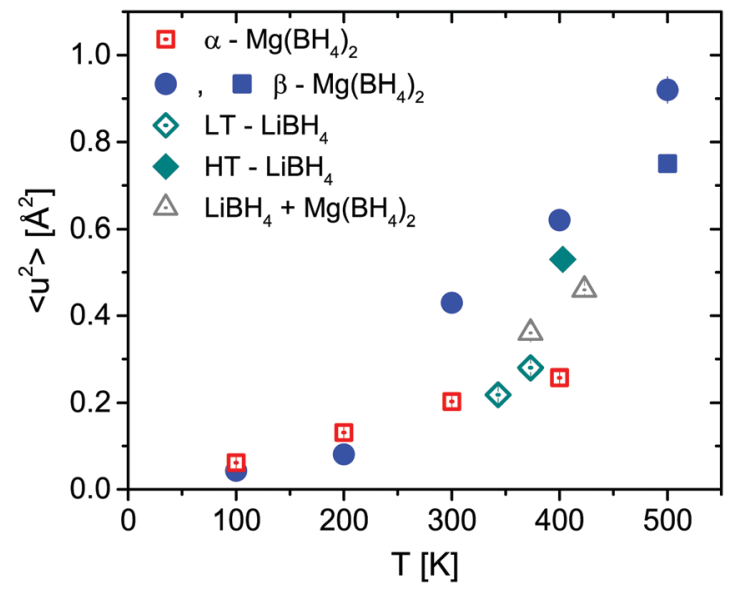

Fig. 9 Mean square displacement $\left\langle u^{2}\right\rangle$ as a function of temperature for $\mathrm{LiBH}_{4}, \alpha$ - and $\beta-\mathrm{Mg}\left(\mathrm{BH}_{4}\right)_{2}$ and the mixture. The vertical error bars denote $\pm 1 \sigma$.

keeping in mind that $\Gamma_{i}$ originate from hindered rotation modes and thus are an average over different sites. Usually, the temperature dependence of the jump frequency is used to estimate the apparent activation energy $E_{\mathrm{a}}$ of the motion, assuming an Arrhenius type behaviour. In the case of $\alpha-\mathrm{Mg}\left(\mathrm{BH}_{4}\right)_{2}$, the temperature independent width of the $\Gamma_{i}$ would yield to a unrealistically low value of $E_{\mathrm{a}}$. Apparently, the differences in two crystal structures are sufficient to effectively lock the $\left[\mathrm{BH}_{4}\right]$ tetrahedra in position in the $\alpha$-phase while enabling more degrees of freedom in the $\beta$-phase. These differences must have their origin in the arrangement of the $\mathrm{Mg}-\left[\mathrm{BH}_{4}\right]$ coordination polyhedra. The low energies probed in the current experiments are characteristic for acoustic and optical modes within the $\mathrm{Mg}-\left[\mathrm{BH}_{4}\right]$ framework ${ }^{7}$ while the (pure) vibrational frequencies of the $\left[\mathrm{BH}_{4}\right]$ units have been reported to be around approximately $65 \mathrm{meV}^{48,49}$ The internal bending and stretching modes of the $\left[\mathrm{BH}_{4}\right]$ tetrahedra are at even higher energies and IR and Raman spectroscopy data show that the bending and stretching modes of the $\left[\mathrm{BH}_{4}\right]$ are quite similar for the $\alpha$ - and $\beta$-modifications. ${ }^{9}$ However, the long range arrangement of the $\mathrm{B}-\mathrm{H}_{2}-\mathrm{Mg}-\mathrm{H}_{2}-\mathrm{B}$-units and the resulting $3 \mathrm{D}$ network is different for the two polymorphs. ${ }^{39}$ In particular, the range of $\mathrm{Mg}-\mathrm{H}$ distances observed in $\beta-\mathrm{Mg}\left(\mathrm{BH}_{4}\right)_{2}$ is slightly larger compared to the $\alpha$-phase $\left(\beta: d_{\mathrm{Mg}-\mathrm{H}}=1.90-2.19 \AA, \alpha: 1.92-2.16 \AA\right.$ ) and the intermolecular $\mathrm{H} \cdots \mathrm{H}$ distance between adjacent $\left[\mathrm{BH}_{4}\right]$ units is in average shorter in the $\alpha$-phase. ${ }^{9,50}$ Additionally, the average distance between $\mathrm{B}$ and $\mathrm{Mg}$ is larger in the $\beta$-polymorph compared to the $\alpha$-phase $\left(\beta\right.$ : $d_{\mathrm{Mg}-\mathrm{B}}=2.34-2.49 \AA$ and $\alpha: 2.39-2.45 \AA$ ). Although both polymorphs show a chainlike structure and the same $\mathrm{Mg}-\left[\mathrm{BH}_{4}\right]-\mathrm{Mg}$ local environment, the different crystallographic distances between $\mathrm{B}, \mathrm{Mg}$, and $\mathrm{H}$ are at the origin of the different vibrational and reorientational dynamics. The mutual repulsion of the negatively charged hydrogen atoms together with a covalent character of the $\mathrm{Mg}-\mathrm{H}$ bond prevents the reorientation of adjacent $\left[\mathrm{BH}_{4}\right]$ units and this can be at the origin of the lower mobility observed in the $\alpha$-phase. On the other hand, once the material is in the $\beta$-phase, the dynamic reorientation of the $\left[\mathrm{BH}_{4}\right]$ units might prevent the rearrangement of the $\mathrm{Mg}-\left[\mathrm{BH}_{4}\right]$ framework to the $\alpha$-configuration down to low temperatures. $\left[\mathrm{BH}_{4}\right]$ rotations remain substantially activated in the $\beta$-phase at least to $200 \mathrm{~K}$, and at this point, kinetics of the first order structural phase transition has slowed down considerably. Differences in the dynamics of the $\left[\mathrm{BH}_{4}\right]$ units have also been reported from NMR measurements ${ }^{41,42}$ which found higher mobility and faster rotations in $\beta-\mathrm{Mg}\left(\mathrm{BH}_{4}\right)_{2}$ compared to the $\alpha$-phase. In fact, the latter shows a much higher activation energy for reorientations compared to the $\beta$-polymorph, and the rotational dynamics is one order of magnitude slower.

\section{$4.2 \mathrm{LiBH}_{4}$}

$\mathrm{LiBH}_{4}$ was measured at temperatures below and above its crystal phase transition at $381 \mathrm{~K}$. Below $381 \mathrm{~K}, \mathrm{LiBH}_{4}$ is in the hexagonal LT-modification and the neutron spectrum consists of a quasielastic component originating from jump rotations, and a vibrational part with an explicit feature centered around $9 \mathrm{meV}$. The spectra are shown in Fig. 10, measurements were taken at $\lambda_{3}=2.5 \AA$. Above $381 \mathrm{~K}$, the sample is in the HT-modification, and the scattering intensity is dominated by a significantly broadened quasielastic contribution. These data are in agreement with previously published results on $\mathrm{LiBH}_{4} \cdot{ }^{20,35}$ In contrast to $\mathrm{Mg}\left(\mathrm{BH}_{4}\right)_{2}$, the crystal phase transition in $\mathrm{LiBH}_{4}$ is fully reversible with temperature. The same procedure as described above was used to analyze the data. In the LT-phase, data were modeled using one quasielastic component with characteristic width, $\Gamma_{1}$ stemming from rotations, the elastic contribution and a vibrational background. The latter was modeled either by a DHO + (broad Lorentzian) in the LT-phase or a broad Lorentzian in the HT-phase.

The width, $\Gamma_{1}$, of the quasielastic component is independent of the momentum transfer $Q$. The values are summarized in Table 3 and are in good agreement with previous reports on $\mathrm{LiBH}_{4} \cdot{ }^{20,35}$

The structure factors EISF, QISF $_{L_{1}}$ and QISF ${ }_{\text {vib }}$ are plotted in Fig. 11. For the evaluation, simultaneous fit using eqn (7)-(9)

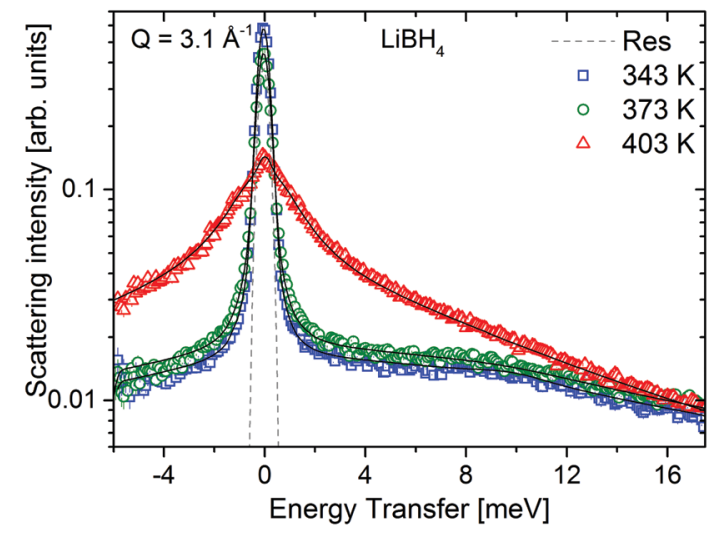

Fig. $10 \mathrm{LiBH}_{4}: S(Q, \omega)$ at $Q=3.1 \AA^{-1}$ and at $343 \mathrm{~K}$ (blue squares), $373 \mathrm{~K}$ (green circles) and $403 \mathrm{~K}$ (red triangles). The dashed line is the resolution function measured with a vanadium standard. The solid black lines represent fits to the data. The vertical error bars denote $\pm 1 \sigma$. 
Table $3 \mathrm{HWHM} \Gamma_{1}$ of $\mathrm{LiBH}_{4}$ in the LT- and HT-modifications. The mean resident time is calculated according to the jump rotational model at different temperatures (see the ESI)

\begin{tabular}{llc}
\hline$T[\mathrm{~K}]$ & $\Gamma_{1, \mathrm{LiBH}_{4}}[\mathrm{meV}]$ & $\tau[\mathrm{ps}]$ \\
\hline 343 & $0.14 \pm 0.02$ & $7 \pm 1$ \\
373 & $0.21 \pm 0.02$ & $3.1 \pm 0.3$ \\
403 & $1.43 \pm 0.09$ & $0.46 \pm 0.03$
\end{tabular}

and $A_{0}(Q)$ of the previously reported rotation modes were employed. At $343 \mathrm{~K}$, a rotation around the $C_{3}$ axis was assumed, ${ }^{20}$ and at $403 \mathrm{~K}$ the orbit exchange model (where the $\left[\mathrm{BH}_{4}\right]$ units rotate quasi free around one of the $C_{3}$-symmetry axes with only occasional flips of that axis $^{20}$ ), in agreement with previous results. The structure factors obtained at $373 \mathrm{~K}$ already appear to be somewhat "in between" the lower and higher temperature measurements, indicating that the low energy dynamics are changing below the crystal phase transition. The extracted structure factors are inconsistent with rotations solely around the $C_{3}$-symmetry axis of the tetrahedra but a simultaneous fit of EISF, QISF and QISF $_{\text {vib }}$ assuming tumbling rotational motion yielded satisfactory results. The mean square displacements $\left\langle u^{2}\right\rangle$ at 343 and $373 \mathrm{~K}$ are $\sim 0.2-0.3 \AA^{2}$, and the value strongly increases to $0.53 \pm 0.01 \AA^{2}$ at $403 \mathrm{~K}$. Fig. 9 shows the mean square displacement of $\mathrm{LiBH}_{4}$, together with the values obtained for $\alpha$ - and $\beta-\mathrm{Mg}\left(\mathrm{BH}_{4}\right)_{2}$. It should be noted that the values obtained for the LT-modification are comparable with $\alpha-\mathrm{Mg}\left(\mathrm{BH}_{4}\right)_{2}$, while HT-LiBH ${ }_{4}$ resembles $\beta-\mathrm{Mg}\left(\mathrm{BH}_{4}\right)_{2}$.

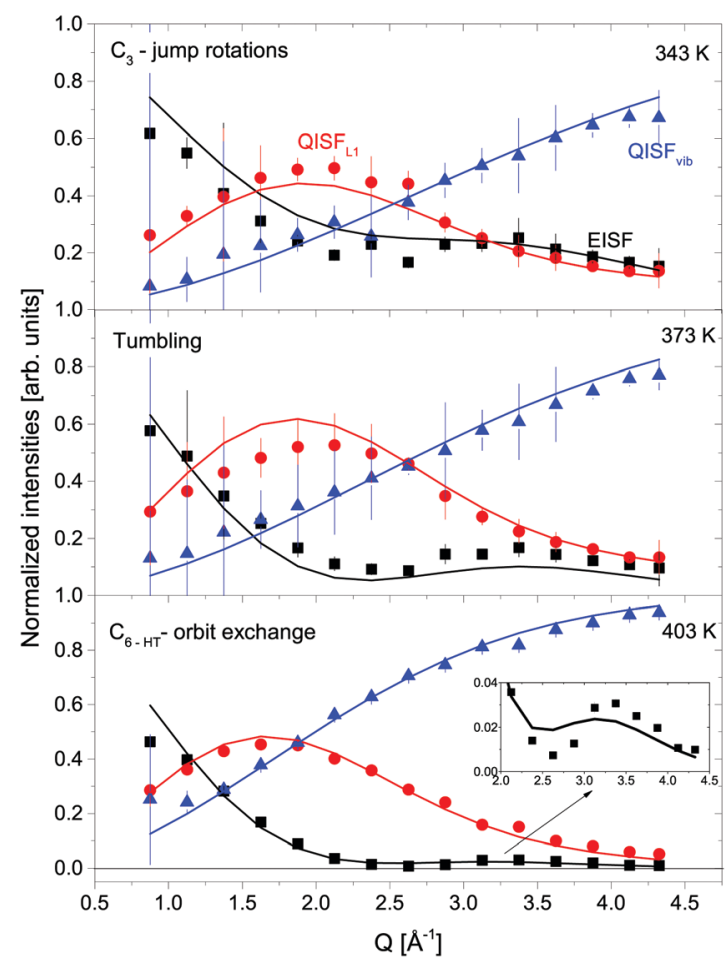

Fig. $11 \mathrm{LiBH}_{4}$ : normalized intensities at different temperatures (from top to bottom): EISF (black squares), QISF $_{L_{1}}$ (red circles) and QISF $_{\text {vib }}$ (blue triangles). Solid black lines represent the fit to the data according to different $A_{0}(Q)$, see the text for details. Vertical error bars denote $\pm 1 \sigma$.

\section{$4.3 \mathrm{LiBH}_{4}+\alpha-\mathrm{Mg}\left(\mathrm{BH}_{4}\right)_{2}$}

The mixture $\mathrm{LiBH}_{4}+\alpha-\mathrm{Mg}\left(\mathrm{BH}_{4}\right)_{2}(1: 1$ molar ratio) was measured at $\lambda_{2}=3.5 \AA$ at temperatures between 373 and $500 \mathrm{~K}$, i.e. below and above the structural phase transition of the constituents, the data are shown in Fig. 12. The slightly better energy resolution was chosen to enable a better discrimination of the narrow quasielastic components compared to measurements at $\lambda_{2}=2.5 \AA$. As for the pure compounds before, the spectra are composed of quasielastic and inelastic components, most prominently, the inelastic excitation of $\alpha-\mathrm{Mg}\left(\mathrm{BH}_{4}\right)_{2}$ at $4.2 \mathrm{meV}$ is observed. The data analysis therefore assumed a physical mixture of $\mathrm{LiBH}_{4}$ and $\mathrm{Mg}\left(\mathrm{BH}_{4}\right)_{2}$, each in the respective crystal modification expected at the given temperature. Since the neutron scattering signal originates almost exclusively from the hydrogen atoms in the sample, the composite spectrum can be assumed to contain $2 / 3 \mathrm{Mg}\left(\mathrm{BH}_{4}\right)_{2}$ like features and $1 / 3$ stemming from $\mathrm{LiBH}_{4}$. Such an ansatz yields a reasonable description of the measured $S(Q, \omega)$ for temperatures below $500 \mathrm{~K}$ as can be seen in Fig. 13. The graph shows the measured data together with the total fit function, as well as the split into the quasielastic and vibrational components. At $373 \mathrm{~K}, L_{1}$ describes the rotational contribution of $\alpha-\mathrm{Mg}\left(\mathrm{BH}_{4}\right)_{2}$ and LT- $\mathrm{LiBH}_{4}$ (denoted $\Gamma_{2, \alpha}$ and $\Gamma_{1, \mathrm{LiBH}_{4}}$ in the above sections), however, due to the closeness of the expected width, a distinction between $\mathrm{Mg}\left(\mathrm{BH}_{4}\right)_{2}$ and $\mathrm{LiBH}_{4}$ could not be done. DHO and $L_{\mathrm{V}}$ are attributed to the vibrational part of $\alpha-\mathrm{Mg}\left(\mathrm{BH}_{4}\right)_{2}$ and $\mathrm{LiBH}_{4}$, respectively. At $423 \mathrm{~K}, \mathrm{LiBH}_{4}$ has undergone the phase transition to the HT-phase, while $\mathrm{Mg}\left(\mathrm{BH}_{4}\right)_{2}$ remains in the $\alpha$-modification. As can be seen in Fig. 13, a further quasielastic contribution is observed whose width $\Gamma_{2} \sim 1.6 \mathrm{meV}$ is reminiscent of the quasielastic component $\Gamma_{1, \mathrm{LiBH}_{4}}$ at $403 \mathrm{~K}$.

The elastic structure factors EISF, $\mathrm{QISF}_{i}$ and $\mathrm{QISF}_{\text {vib }}$ were obtained and the results are shown in Fig. 14. Assuming a 2/3:1/3 ratio for the $\mathrm{Mg}\left(\mathrm{BH}_{4}\right)_{2}$ and $\mathrm{LiBH}_{4}$ like features, the structure factors follow the set of equations (for details see the ESI $\dagger$ ):

$$
\mathrm{EISF}=F(Q)\left[\frac{1}{3} B_{0}(Q)+\frac{2}{3}\left[p+(1-p) A_{0}(Q)\right]\right]
$$

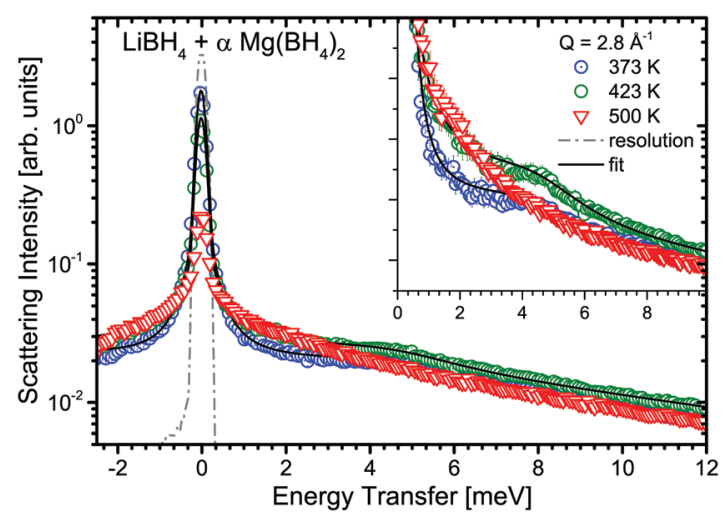

Fig. $12 \mathrm{LiBH}_{4}+\alpha-\mathrm{Mg}\left(\mathrm{BH}_{4}\right)_{2}: S(Q, \omega)$ of an 1:1 molar mixture at 373,423 and $500 \mathrm{~K}$ at $Q=2.8 \AA^{-1}$. The dashed line represents the resolution function of the instrument. The inset zooms into the energy transfer region around $4 \mathrm{meV}$. Solid black lines are fits to the data. The vertical error bars denote $\pm 1 \sigma$. 

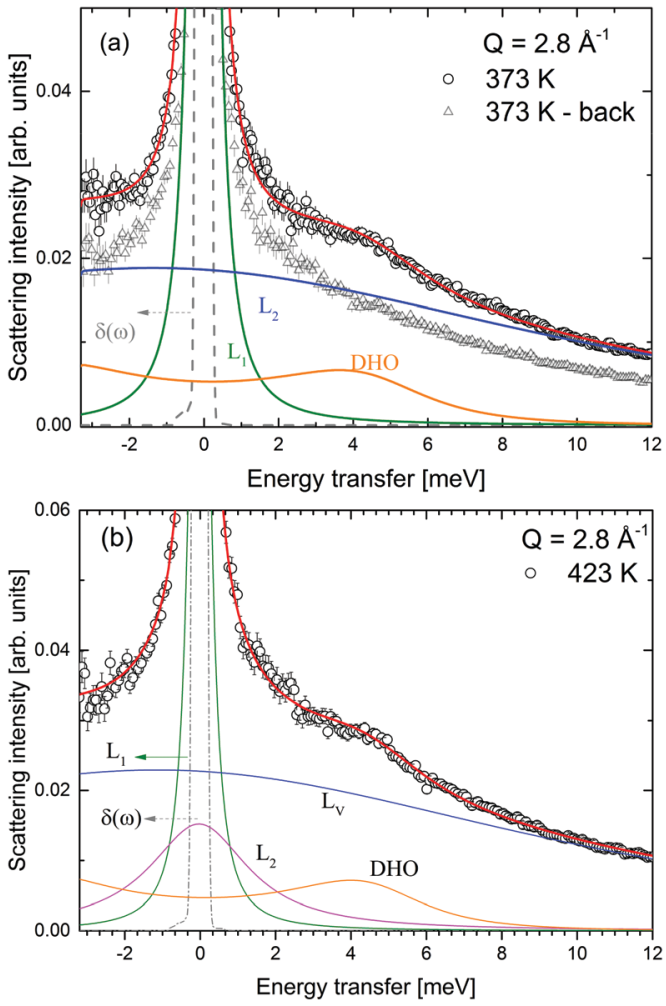

Fig. $13 \mathrm{LiBH}_{4}+\alpha-M g\left(\mathrm{BH}_{4}\right)_{2}: S(Q, \omega)$ (open symbols), fit to the data (red solid line) and the respective contributions to the spectra at (a) $373 \mathrm{~K}$ and (b) $423 \mathrm{~K}$. In panel (a), the data after cooling the sample from 500 to $373 \mathrm{~K}$ (triangles) are also shown. The vertical error bars denote $\pm 1 \sigma$.

$$
\begin{gathered}
\mathrm{QISF}_{373 \mathrm{~K}}=F(Q)\left[\frac{1}{3}\left[1-B_{0}(Q)\right]+\frac{2}{3}(1-p)\left[1-A_{0}(Q)\right]\right] \\
\mathrm{QISF}_{423 \mathrm{~K}, 1}=F(Q)\left[\frac{2}{3}(1-p)\left[1-A_{0}(Q)\right]\right] \\
\mathrm{QISF}_{423 \mathrm{~K}, 2}=F(Q)\left[\frac{1}{3}\left[1-B_{0}(Q)\right]\right]
\end{gathered}
$$

$$
\mathrm{QISF}_{\mathrm{vib}}=1-F(Q)
$$

where the only free parameters are $F(Q)$, the average DebyeWaller Factor and $1-p$, the fraction of activated rotations in $\alpha-\mathrm{Mg}\left(\mathrm{BH}_{4}\right)_{2}$. Depending on temperature, one or two distinct quasielastic contributions were identified and the corresponding expressions for $\operatorname{QISF}_{373 \mathrm{~K}}$ and $\operatorname{QISF}_{423 \mathrm{~K}, i},(i=1,2)$ were used. The rotational elastic structure factors $A_{0}(Q)$ and $B_{0}(Q)$ were chosen as for the single compounds, i.e. $A_{0}(Q)$ describing rotations around the $C_{2} / C_{3}$ symmetry axis in $\mathrm{Mg}\left(\mathrm{BH}_{4}\right)_{2}$ at 373 and $423 \mathrm{~K}$, while $B_{0}(Q)$ describes rotations in $\mathrm{LiBH}_{4}$ which change from tumbling motion to the orbit exchange. The results of the simultaneous fit are plotted in Fig. 14 (solid lines). The average mean square displacements $\left\langle u^{2}\right\rangle$ are $0.36 \pm 0.02 \AA^{2}$ and $0.46 \pm 0.01 \AA^{2}$ at 373 and $423 \mathrm{~K}$, while the fraction of activated rotations in $\mathrm{Mg}\left(\mathrm{BH}_{4}\right)_{2}, 1-p$, amounts
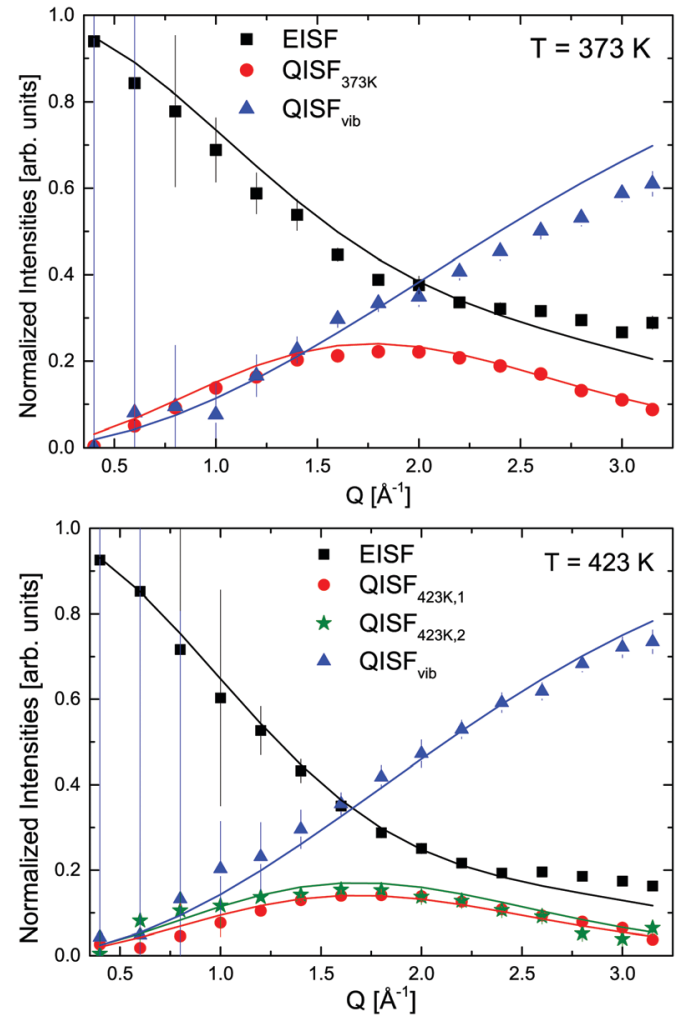

Fig. $14 \mathrm{LiBH}_{4}+\alpha-\mathrm{Mg}\left(\mathrm{BH}_{4}\right)_{2}$ : EISF, QISF $F_{i}$ and $\mathrm{QISF}_{\text {vib }}$ obtained from an 1:1 molar ratio for 373 and $423 \mathrm{~K}$ (symbols). Solid lines describe simultaneous fits to the data according to eqn (10)-(14). The vertical error bars denote $\pm 1 \sigma$

to $0.21 \pm 0.04$ and $0.66 \pm 0.03$. These values are in very good agreement with the values found for the pure compounds and underline that during ball milling, $\mathrm{LiBH}_{4}+\alpha-\mathrm{Mg}\left(\mathrm{BH}_{4}\right)_{2}$ remains as a physical mixture of the powders. The average $\left\langle u^{2}\right\rangle$ values lie between the values found for the pure compounds, with the exception of $373 \mathrm{~K}$ : here, the value is slightly higher than would be expected for the mixture.

These conclusions are supported by a plot of the imaginary part of the dynamic susceptibility. Fig. 15 shows $-\chi^{\prime \prime}$ for the pure compounds and the mixture. In panel (d), the weighted average of $\alpha-\mathrm{Mg}\left(\mathrm{BH}_{4}\right)_{2}$ and $\mathrm{LiBH}_{4}$ of $-\chi^{\prime \prime}$ is calculated $\left(2 / 3 \alpha-\mathrm{Mg}\left(\mathrm{BH}_{4}\right)_{2}+1 / 3 \mathrm{LiBH}_{4}\right.$, according to the number of hydrogen atoms in each of the constituents). Comparison with the measured data, displayed in panel (c), shows that the low energy excitation spectrum in the ball milled mixture can be well described as the weighted average of the single compounds. At $373 \mathrm{~K}$, it is a mixture of $\alpha-\mathrm{Mg}\left(\mathrm{BH}_{4}\right)_{2}$ and LT- $\mathrm{LiBH}_{4}$, at $423 \mathrm{~K}$, it is a mixture of $\alpha-\mathrm{Mg}\left(\mathrm{BH}_{4}\right)_{2}$ and $\mathrm{HT}-\mathrm{LiBH}_{4}$, and finally, at $500 \mathrm{~K}$, it is described as a superposition of $\beta-\mathrm{Mg}\left(\mathrm{BH}_{4}\right)_{2}$ and $\mathrm{HT}^{-} \mathrm{LiBH}_{4}$. The latter indicates that even in the melted state, the main characteristics of the individual constituents prevail, although the measured curve shows a slightly larger decrease at energies above $8 \mathrm{meV}$ which is not seen in the calculated curve. It should be noted that hydrogen decomposition started at that point, and no correction for the loss in scattering intensity has been done. After cooling (to $373 \mathrm{~K}$, solid line in 


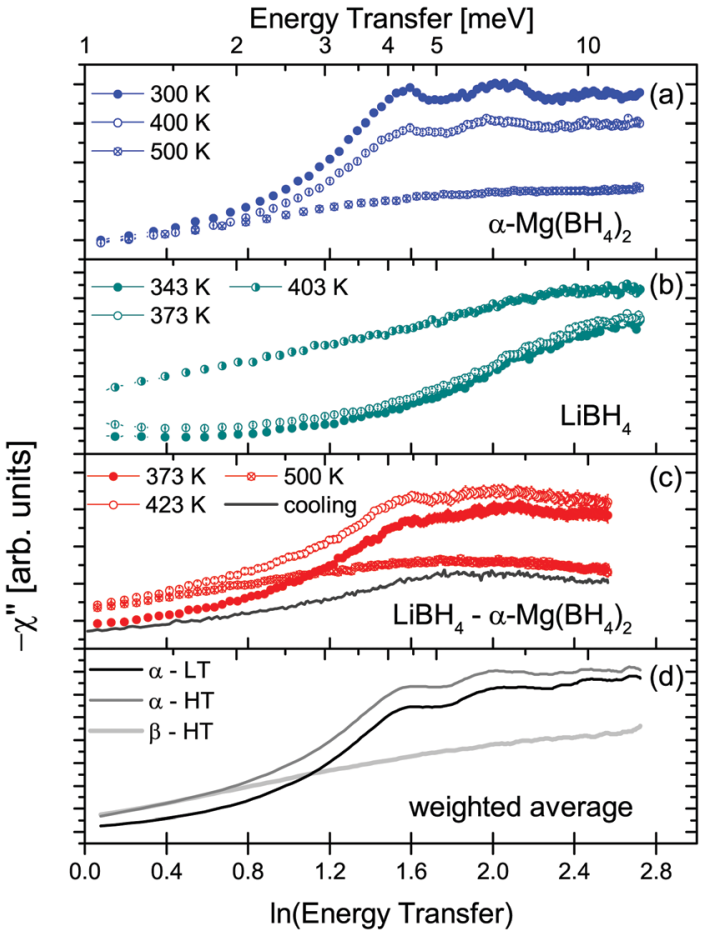

Fig. $15-\chi^{\prime \prime}$ as a function of In(energy transfer) for (a) $\alpha-M g\left(\mathrm{BH}_{4}\right)_{2}$, (b) $\mathrm{LiBH}_{4}$ and the mixture (c) $\mathrm{LiBH}_{4}+\mathrm{Mg}\left(\mathrm{BH}_{4}\right)_{2}$. The lines in the bottom figure are the calculated weighted average, $2 / 3 \mathrm{Mg}\left(\mathrm{BH}_{4}\right)_{2}+1 / 3 \mathrm{LiBH}_{4}$, of the pure compounds. The vertical error bars denote $\pm 1 \sigma$.

Fig. 15(c) and data in Fig. 13(a)), the low energy spectrum is slightly changed, with a broad excitation between 5-8 meV which could be a hint towards the formation of a mixed phase. Further studies are needed to characterize the dynamics of the mixture at $500 \mathrm{~K}$ and after cooling. It should be noted that the melted state is accompanied by a distinct increase of the quasielastic contribution, as can be seen in Fig. 12. The elastic scattering contribution decreases significantly, however, it does not disappear completely. This is an indication that even in the melted state, there are still components that are too slow to show translatory movement in the experimental time window. However, a tentative data analysis (not shown in this work) has been performed to understand the nature of the reorientational motions at this temperature. ${ }^{51}$ Two diffusion-like processes have been identified (typical of melted phases): one with a self-diffusion coefficient in the same order of magnitude of $\left[\mathrm{BH}_{4}\right]$ anion diffusion reported for molten $\mathrm{LiBH}_{4},{ }^{52}$ and one with a diffusion coefficient one order of magnitude larger, not yet attributed. Since hydrogen decomposition also started, no further analysis or separation of various scattering contributions has been undertaken for this temperature, due to the uncertain nature of the amount and composition of the decomposition products.

\section{Conclusions}

The complex borohydrides $\mathrm{Mg}\left(\mathrm{BH}_{4}\right)_{2}, \mathrm{LiBH}_{4}$, and their $1: 1$ molar mixture have been investigated using neutron spectroscopy.
For all investigated samples, the low energy transfer spectra are characterized by quasielastic features originating from jump rotation processes, and by vibrational lattice modes. The detailed dynamic response is closely linked to the respective crystal modification. Most striking is the difference between the dynamic properties of $\alpha$ - and $\beta-\mathrm{Mg}\left(\mathrm{BH}_{4}\right)_{2}$. Although the local $\mathrm{Mg}-\left[\mathrm{BH}_{4}\right]$ coordination in both phases is quite similar and jump rotations around the same symmetry axis are observed, the long range coordination plays a decisive role for the lattice dynamics and the activated rotation motions of the $\left[\mathrm{BH}_{4}\right]$ tetrahedra. Vice versa, the entropic contribution of the $\left[\mathrm{BH}_{4}\right]$ units and of the lattice dynamics at high temperatures might be at the origin for the metastability of the $\beta$-polymorph upon cooling. In $\mathrm{LiBH}_{4}$, the first order structural phase transition is accompanied by a change in the local reorientation of the $\left[\mathrm{BH}_{4}\right]$ units, described as order-disorder transition. Notably, the $\left[\mathrm{BH}_{4}\right]$ rotational symmetry already changes below the phase transition temperature, reminiscent of the pretransition behaviour observed employing Raman spectroscopy. ${ }^{53}$ The ball milled mixture of $\mathrm{LiBH}_{4}+\alpha-\mathrm{Mg}\left(\mathrm{BH}_{4}\right)_{2}$ remains a physical mixture of the two compounds up to the melting temperature, and the characteristic dynamics of each constituent can be observed.

\section{Conflicts of interest}

There are no conflicts to declare.

\section{References}

1 A. Züttel, P. Wenger, S. Rentsch, P. Sudan, P. Mauron and C. Emmenegger, J. Power Sources, 2003, 118, 1-7.

2 S. Orimo, Y. Nakamori, G. Kitahara, K. Miwa, N. Ohba, S. Towata and A. Züttel, J. Alloys Compd., 2005, 404-406, 427-430.

3 J.-H. Her, P. W. Stephens, Y. Gao, G. L. Soloveichik, J. Rijssenbeek, M. Andrus and J.-C. Zhao, Acta Crystallogr., Sect. B: Struct. Sci., 2007, 63, 561-568.

4 K. Chłopek, C. Frommen, A. Léon, O. Zabara and M. Fichtner, J. Mater. Chem., 2007, 17, 3496-3503.

5 J.-H. Kim, S.-A. Jin, J.-H. Shim and Y. W. Cho, Scr. Mater., 2008, 58, 481-483.

6 V. Ozolins, E. H. Majzoub and C. Wolverton, Phys. Rev. Lett., 2008, 100, 135501.

7 J. Voss, J. S. Hummelshøj, Z. Oodziana and T. Vegge, J. Phys.: Condens. Matter, 2009, 21, 012203.

8 X.-F. Zhou, A. R. Oganov, G.-R. Qian and Q. Zhu, Phys. Rev. Lett., 2012, 109, 245503.

9 O. Zavorotynska, A. El-Kharbachi, S. Deledda and B. C. Hauback, Int. J. Hydrogen Energy, 2016, 41, 14387-14403.

10 Y. Filinchuk, B. Richter, T. R. Jensen, V. Dmitriev, D. Chernyshov and H. Hagemann, Angew. Chem., Int. Ed. Engl., 2011, 50, 11162-11166.

11 F. Buchter, Z. Oodziana, A. Remhof, O. Friedrichs, A. Borgschulte, P. Mauron, A. Züttel, D. Sheptyakov, 
G. Barkhordarian, R. Bormann, K. Chłopek, M. Fichtner, M. Sørby, M. Riktor, B. Hauback and S. Orimo, J. Phys. Chem. B, 2008, 112, 8042-8048.

12 Y. Filinchuk, E. Rönnebro and D. Chandra, Acta Mater., 2009, 57, 732-738.

13 T. Noritake, M. Aoki, M. Matsumoto, K. Miwa, S. Towata, H.W. Li and S. Orimo, J. Alloys Compd., 2010, 491, 57-62.

14 I. Llamas-Jansa, O. Friedrichs, M. Fichtner, E. G. Bardaji, A. Züttel and B. C. Hauback, J. Phys. Chem. C, 2012, 116, 13472-13479.

15 Y. Filinchuk, D. Chernyshov and R. Černý, J. Phys. Chem. C, 2008, 112, 10579-10584.

16 P. Fischer and A. Züttel, Mater. Sci. Forum, 2004, 287-290.

17 G. Renaudin, S. Gomes, H. Hagemann, L. Keller and K. Yvon, J. Alloys Compd., 2004, 375, 98-106.

18 Z. Oodziana and M. J. van Setten, Phys. Rev. B: Condens. Matter Mater. Phys., 2010, 81, 024117.

19 N. Verdal, M. R. Hartman, T. Jenkins, D. J. DeVries, J. J. Rush and T. J. Udovic, J. Phys. Chem. C, 2010, 114, 10027-10033.

20 N. Verdal, T. J. Udovic and J. J. Rush, J. Phys. Chem. C, 2012, 116, 1614-1618.

21 T. J. Udovic, N. Verdal, J. J. Rush, D. J. De Vries, M. R. Hartman, J. J. Vajo, A. F. Gross and A. V. Skripov, J. Alloys Compd., 2013, 580, S47-S50.

22 N. Verdal, T. J. Udovic, W. Zhou, J. J. Rush, D. J. De Vries and M. R. Hartman, J. Phys. Chem. C, 2013, 117, 876-883.

23 A. Borgschulte, R. Gremaud, A. Züttel, P. Martelli, A. Remhof, A. J. Ramirez-Cuesta, K. Refson, E. G. Bardají, W. Lohstroh, M. Fichtner, H. Hagemann and M. Ernst, Phys. Rev. B: Condens. Matter Mater. Phys., 2011, 83, 024102.

24 Y. Nakamori, K. Miwa, A. Ninomiya, H. Li, N. Ohba, S. Towata, A. Züttel and S. Orimo, Phys. Rev. B: Condens. Matter Mater. Phys., 2006, 74, 045126.

25 D. Ravnsbaek, Y. Filinchuk, Y. Cerenius, H. Jakobsen, F. Besenbacher, J. Skibsted and T. Jensen, Angew. Chem., 2009, 121, 6787-6791.

26 L. H. Rude, T. K. Nielsen, D. B. Ravnsbaek, U. Bösenberg, M. B. Ley, B. Richter, L. M. Arnbjerg, M. Dornheim, Y. Filinchuk, F. Besenbacher and T. R. Jensen, Phys. Status Solidi A, 2011, 208, 1754-1773.

27 E. Nickels, M. Jones, W. David, S. Johnson, R. Lowton, M. Sommariva and P. Edwards, Angew. Chem., Int. Ed. Engl., 2008, 47, 2817-2819.

28 P. Schouwink, V. D’Anna, M. B. Ley, L. M. Lawson Daku, B. Richter, T. R. Jensen, H. Hagemann and R. Černý, J. Phys. Chem. C, 2012, 116, 10829-10840.

29 G. Capurso, F. Agresti, L. Crociani, G. Rossetto, B. Schiavo, A. Maddalena, S. L. Russo and G. Principi, Int. J. Hydrogen Energy, 2012, 37, 10768-10773.

30 E. G. Bardají, Z. Zhao-Karger, N. Boucharat, A. Nale, M. J. van Setten, W. Lohstroh, E. Röhm, M. Catti and M. Fichtner, J. Phys. Chem. C, 2011, 115, 6095-6101.
31 Z.-Z. Fang, X.-D. Kang, P. Wang, H.-W. Li and S.-I. Orimo, J. Alloys Compd., 2010, 491, L1-L4.

32 L. Zhang, J. Zheng, X. Xiao, X. Fan, X. Huang, X. Yang and L. Chen, RSC Adv., 2017, 7, 36852-36859.

33 N. Verdal, T. J. Udovic and J. J. Rush, J. Phys. Chem. C, 2012, 116, 1614-1618.

34 N. Verdal, T. J. Udovic, J. J. Rush, H. Wu and A. V. Skripov, J. Phys. Chem. C, 2013, 117, 12010-12018.

35 A. Remhof, Z. Oodziana, P. Martelli, O. Friedrichs, A. Züttel, A. V. Skripov, J. P. Embs and T. Strässle, Phys. Rev. B: Condens. Matter Mater. Phys., 2010, 81, 214304.

36 R. Gremaud, A. Züttel, A. Borgschulte, A. Ramirez-Cuesta, K. Refson and D. Colognesi, Chem. Phys., 2013, 427, 22-29.

37 J.-P. Soulié, G. Renaudin, R. Černý and K. Yvon, J. Alloys Compd., 2002, 346, 200-205.

38 F. Buchter, Z. Oodziana, P. Mauron, A. Remhof, O. Friedrichs, A. Borgschulte, A. Züttel, D. Sheptyakov, T. Strässle and A. J. Ramirez-Cuesta, Phys. Rev. B: Condens. Matter Mater. Phys., 2008, 78, 094302.

39 Y. Filinchuk, R. Černý and H. Hagemann, Chem. Mater., 2009, 21, 925-933.

40 A. V. Skripov, A. V. Soloninin, O. A. Babanova, H. Hagemann and Y. Filinchuk, J. Phys. Chem. C, 2010, 114, 12370-12374.

41 A. V. Soloninin, O. A. Babanova, A. V. Skripov, H. Hagemann, B. Richter, T. R. Jensen and Y. Filinchuk, J. Phys. Chem. C, 2012, 116, 4913-4920.

42 D. T. Shane, L. H. Rayhel, Z. Huang, J.-C. Zhao, X. Tang, V. Stavila and M. S. Conradi, J. Phys. Chem. C, 2011, 115, 3172-3177.

$43 \mathrm{~W}$. Lohstroh and Z. Evenson, Journal of large-scale research facilities, 2015, 1, 1-3.

44 T. Unruh, J. Neuhaus and W. Petry, Nucl. Instrum. Methods Phys. Res., Sect. A, 2007, 580, 1414-1422.

45 L. Silvi, E. Röhm, M. Fichtner, W. Petry and W. Lohstroh, Phys. Chem. Chem. Phys., 2016, 18, 14323-14332.

46 R. Hempelmann, Quasielastic Neutron Scattering and Solid State Diffusion, Clarendon Press, 2000.

47 K. Sköld, J. Chem. Phys., 1968, 49, 2443-2445.

48 A. Giannasi, D. Colognesi, L. Ulivi, M. Zoppi, A. J. RamirezCuesta, E. G. Bardají, E. Röhm and M. Fichtner, J. Phys. Chem. A, 2010, 114, 2788-2793.

49 H. Hagemann, V. D’Anna, J.-P. Rapin, R. Černý, Y. Filinchuk, K. C. Kim, D. S. Sholl and S. F. Parker, J. Alloys Compd., 2011, 509(Suppl. 2), S688-S690.

50 Y. Filinchuk, R. Černý and H. Hagemann, Chem. Mater., 2009, 21, 925-933.

51 L. Silvi, PhD thesis, Technische Universität München, 2017. 52 P. Martelli, A. Remhof, A. Borgschulte, P. Mauron, D. Wallacher, E. Kemner, M. Russina, F. Pendolino and A. Züttel, J. Phys. Chem. A, 2010, 114, 10117-10121.

53 H. Hagemann, Y. Filinchuk, D. Chernyshov and W. van Beek, Phase Transitions, 2009, 82, 344-355. 